\title{
Evaluation of inflammatory biomarkers, carotid intima- media thickness and cardiovascular risk in HIV-1 treatment-naive patients
}

\author{
Priscila Valéria do Carmo Carvalho[1], Júlia Fonseca de Morais Caporali ${ }^{[2],}$ \\ Érica Leandro Marciano Vieira ${ }^{[3]}$, Nathalia Sernizon Guimarães ${ }^{[1]}$, \\ Marise Oliveira Fonseca ${ }^{[2]}$ and Unai Tupinambás ${ }^{[1],[2]}$
}

[1]. Programa de Pós-Graduação em Ciênicas da Saúde: Infectologia e Medicina Tropical, Faculdade de Medicina, Universidade Federal de Minas Gerais, Belo Horizonte, MG, Brasil.

[2]. Departamento de Clinica Médica, Faculdade de Medicina da Universidade Federal de Minas Gerais. Belo Horizonte, MG, Brasil.

[3]. Laboratório Interdisciplinar de Investigação Médica, Faculdade de Medicina, Universidade Federal de Minas Gerais, Belo Horizonte, MG, Brasil.

\begin{abstract}
Introduction: Mortality among HIV patients is 3-15 times higher than that among the general population. Currently, most deaths are due to non-infectious diseases. Chronic inflammation and adverse events due to antiretroviral therapy play crucial roles in increasing cardiovascular risk (CVR). Methods: This cross-sectional study aimed to evaluate carotid intima-media thickness (CIMT) and inflammatory biomarkers (D-dimer, ADAMTS13, GDF-15, sICAM-1, MPO, myoglobin, NGAL, SAA, sVCAM-1, and p-selectin) among naïve patients. Results: Sixty-seven participants were included: median age, 32 years; males, $82.1 \%$; non-white, 61.1\%; higher education level, 62.7\%; and exposed to HIV through sexual relationship (men who have sex with men), $68.7 \%$. The median viral load and $\mathrm{LTCD}^{+}$value were 42,033 copies $/ \mathrm{mL}$ and $426 \mathrm{cells} / \mathrm{mm}^{3}$. The prevalence of arterial hypertension was $16.4 \%$; those of diabetes mellitus and dyslipidemia were $3 \%$ and $70.1 \%$, respectively. The CIMT was 494.08 $( \pm 96.84 \mathrm{~mm})$. The mean vascular age was $33.2 \pm 18.9$ years, one year longer than the chronological age, without statistical significance. Conclusions: The majority of participants had a low CVR (94\%). After reclassification, considering the CIMT percentiles, 13 (19.4\%) patients had medium/ high CVR, while 54 (80.6\%) patients had low CVR. The difference between the proportions of CVR when considering the CIMT and its corresponding percentile was statistically relevant. Body mass index was the only predictor of higher CVR $(\mathrm{p}=0.03)$. No biomarker was found to predict CVR. People living with HIV have a high prevalence of dyslipidemia before ARV therapy.
\end{abstract}

Keywords: HIV. Cardiovascular risk. Biomarkers. Inflammation. Intima-media thickness.

\section{INTRODUCTION}

Infection caused by human immunodeficiency virus (HIV) is the fifth-leading cause of death among adults worldwide ${ }^{1}$. The policy of universalizing access to antiretroviral therapy (ART) has been determined to impact on patient survival, changing the profile of the epidemic characterized by the reduction of new cases and mortality ${ }^{1}$. Despite this, mortality is still 3 to 15 times higher in the population living with HIV than the general population ${ }^{2-4}$. Although the mortality rate can be attributed to infectious complications, more than half of these deaths are due to non-infectious causes. With the improvement of ART-associated survival, a transition between infectious

Corresponding author: Prof. Unai Tupinambás e-mail: unai@ufmg.br

Received 7 December 2017

Accepted 18 May 2018 and non-infectious complications was noted, increasing the importance of chronic degenerative events $\mathrm{s}^{5-10}$. The reduction in life expectancy among people living with HIV (PLWHIV) is associated with an increased risk of a series of non-AIDS complications, including heart disease, cancer, liver, kidney diseases, bone diseases, and neurocognitive disorders ${ }^{10,11}$. HIV carriers are at 1.5 to 2 times higher risk of cardiac events than the general population $3,8,11,12-21$. This increase may be related to chronic immune-inflammatory activity and immunosenescence in $\mathrm{HIV}^{3,69}$, in addition to the classic risk factors. Inflammatory biomarkers are generally elevated in PLHIV ${ }^{12,22-30}$. These markers have been associated with an increased risk of cardiovascular disease (CVD), opportunistic conditions, and other causes of mortality $7,12,13,22,31-35$. Persistent immune activation and inflammation associated with classical factors play an important role in the etiology of CVDs ${ }^{17}$. The identification of subclinical coronary artery disease, assessed by measuring the carotid intima-media thickness (CIMT), considered as a substitutive marker, may represent an early diagnostic strategy in this 
population $^{18,23-26}$. The CIMT of PLHIV is thicker than that in the uninfected population ${ }^{25,27-29}$. In this context, the present study evaluated the profiles of the inflammatory biomarkers related to CVDs and the intima-media thickness as predictors of CVD risk in human immunodeficiency virus/acquired immunodeficiency syndrome (HIV/AIDS) patients before antiretroviral therapy.

\section{METHODS}

This observational, cross-sectional study was performed among PLWHIV before starting ART, between 2014 and 2015 in a specialized service.

\section{Ethical considerations}

The study protocol was approved by the Research Ethics Committee of the Federal University of Minas Gerais (no. 12649713.4.0000.5149).

The inclusion criteria were: age between 18 and 60 years, and both genders with a diagnosis of HIV infection without the prior use of ART. The exclusion criteria were: lack of completion of the protocol for the collection of clinical or laboratory data, pregnancy, or history of chronic non-controlled diseases.

The following information was collected: sociodemographic (age, gender, race, education, and marital status), lifestyle (smoking, alcoholism, and alcohol abuse through the CAGE questionnaire $)^{36}$, systolic and diastolic blood pressure, anthropometric data (weight and height), and biochemical parameters as fibrinogen, 25-hydroxyvitamin D, lipidogram, blood glucose, polymerase chain reaction (PCR) results, in addition to viral load (HIV-PCR), and LTCD4 ${ }^{+}$lymphocyte count.

The levels of biomarkers related to CVDs were measured using the Human Cardiovascular Disease (Merck Millipore) kit according to the manufacturer's recommendations ${ }^{37}$. Ultrasonography of the carotid arteries was also performed by a single trained examiner, within 10 days after initiation of the treatment. The measurement of CIMT followed the current technical principles ${ }^{26,37-39}$. The values of intima-media thickness were expressed in terms of vascular age, based on the vascular age calculator (VAC) $)^{38}$.

In the descriptive analysis, qualitative variables were summarized as absolute and relative frequencies and quantitative variables were summarized as means and standard deviations or medians and interquartile ranges. The assumption of normality for the probability distribution of the variables was verified using the Shapiro-Wilk test. Comparisons between two quantitative variables were performed using the KruskalWallis test for non-normally distributed variables and analysis of variance for normally distributed variables. The tests were used to compare serum levels of the biomarkers (ADAMTS13, D-dimer, GDF-15, myoglobin, sICAM-1, MPO, p-selectin, lipocalin-2/NGAL, sVCAM-1, and SAA) among the categories of viral load and Framingham risk score. Biomarkers and viral load correlations were analyzed using Spearman's rank correlation test. Receiver operating characteristic (ROC) curve analysis was used to investigate cardiovascular risk prediction and verify the association of biomarkers with cardiovascular risk and viral load. The log-binomial model was used to evaluate whether biomarkers were predictors of cardiovascular risk. The univariate model of each marker was adjusted with the risk variable (yes or no); markers that had $\mathrm{p}$-values $\leq 0.20$ were considered as candidates for the multivariate model. A multivariate model was fitted with all candidates and step-bystep the markers with higher p-values were withdrawn until all significant markers remained at the 0.05 level. The quality of fit of the model was assessed by the deviance and quality measures of the model, i.e., Akaike information criterion, corrected version of the Akaike information criterion, Bayesian information criterion, and consistent Akaike information criterion. The multivariate linear regression model was used to investigate the correlation between the study variables and the thickness of the intima media. It was initiated by univariate adjustment of the simple linear regression model of each group of variables. Within each group, the candidate variables (with $\mathrm{p} \leq 0.20$ ) were selected, adjusting the multivariate models for each group individually with their respective candidate variables and step-by-step, with the variables with the highest p-values being removed until they were all significant at the 0.05 level. The quality of fit was verified by residual analysis (normality, homoscedasticity, and independence). In all applied tests, significance levels of $5 \%$ were used.

\section{RESULTS}

In this study, out of 105 patients who were screened, 5 did not meet the inclusion criteria, and 9 did not undergo laboratory data collection. Among the 91 patients included in the study, 67 (73.6\%) underwent carotid ultrasonography and measurement of biomarkers.

The median age of the participants was 32 (26-41) years, the majority being men who have sex with other men (MSM). Regarding comorbidities, the prevalences of hypertension, diabetes, and dyslipidemia were $16.4 \%, 3 \%$ and $70.1 \%$, respectively. The median viral load was $42,033(16,189-101,069)$ copies $/ \mathrm{mL}$ and the median LTCD4 ${ }^{+}$lymphocyte count was 426 $(262-561) \mathrm{cell} / \mathrm{mm}^{3}$. The median time between diagnosis of HIV infection and initiation of antiretroviral therapy was 4.6 months, ranging from 1 to 301.7 months, as shown in Table 1.

The mean CIMT was $494.08( \pm 96.84 \mathrm{~mm})$. The mean vascular age was $33.2 \pm 18.9$ years, one year longer than the chronological age (32 years), but with no statistical significance. The majority of participants had a low cardiovascular risk (94\%) as measured by the Framingham score (Table 2). According to the consensus, individuals with CIMT values greater than or equal to the 75th percentile are considered as high risk and indicate an increased CVD risk ${ }^{23}$. Thus, after the reclassification, considering the CIMT percentiles, $13(19.4 \%)$ patients had medium/high cardiovascular risk, and $54(80.6 \%)$ patients had low cardiovascular risk. Considering the CIMT measure for the estimation of cardiovascular risk was statistically significant $(p=0.02)$.

ROC curve analysis showed that body mass index was the only predictor of higher cardiovascular risk $(p=0.03$ ) (Table 3). D-dimer and $\mathrm{p}$-selectin presented predictive tendencies $(\mathrm{p}=0.06$ and 0.06 , respectively). D-dimer showed a significant correlation with viral load level, $(\mathrm{r}=-0.389, \mathrm{p}<0.01)$. P-selectin was uncorrelated to 
TABLE 1: Clinical and laboratory characteristics of treatment-naïve people living with HIV, assessed in a reference center, Belo Horizonte, State of Minas Gerais, March 2014 - September 2015.

\begin{tabular}{|c|c|}
\hline Variables & Number=67 \\
\hline $\begin{array}{l}\text { Age } \\
\text { median (interquartile range) }\end{array}$ & $32(26 ; 41)$ \\
\hline $\begin{array}{l}\text { Race, } \mathrm{n}(\%) \\
\text { white } \\
\text { nonwhite }\end{array}$ & $\begin{array}{l}26(39) \\
41(61)\end{array}$ \\
\hline $\begin{array}{l}\text { Education, } \mathrm{n}(\%) \\
\text { illiterate } \\
\text { elementary/ middle school } \\
\text { high school } \\
\text { college }\end{array}$ & $\begin{array}{c}0(0.0) \\
8(12.0) \\
17(25.4) \\
42(62.7)\end{array}$ \\
\hline $\begin{array}{l}\text { Alcohol abuse (CAGE), n=45 } \\
\text { yes } \\
\text { no }\end{array}$ & $\begin{array}{c}4(8.9) \\
41(91.1)\end{array}$ \\
\hline $\begin{array}{l}\text { Tabagism } \\
\text { yes } \\
\text { no }\end{array}$ & $\begin{array}{l}12(17.9) \\
55(82.1)\end{array}$ \\
\hline $\begin{array}{l}\mathrm{SBP}(\mathrm{mmHg}) \\
\text { median* }^{*}\end{array}$ & $120(110 ; 125)$ \\
\hline $\begin{array}{l}\mathrm{DBP}(\mathrm{mmHg}) \\
\text { median }^{*}\end{array}$ & $80(70 ; 80)$ \\
\hline $\begin{array}{l}\text { Triglycerides }(\mathrm{mg} / \mathrm{dL}), \mathrm{n}(\%) \\
<150 \text { normal } \\
\geq 150 \text { abnormal }\end{array}$ & $\begin{array}{l}47(70.1) \\
20(29.9\end{array}$ \\
\hline $\begin{array}{l}\text { HDLc }(\mathrm{mg} / \mathrm{dL}), \mathrm{n}(\%) \\
\text { male, } \mathrm{n}=55 \\
\quad \geq 40 \text { normal } \\
<40 \text { abnormal } \\
\text { female, } \mathrm{n}=12 \\
\quad \geq 50 \text { normal } \\
\quad<50 \text { abnormal }\end{array}$ & $\begin{array}{c}18(32.7) \\
37(67.3) \\
3(25) \\
9(75)\end{array}$ \\
\hline $\begin{array}{l}\text { Total cholesterol (mg/dL), } \mathrm{n}(\%) \\
<200 \text { normal } \\
\geq 200 \text { abnormal }\end{array}$ & $\begin{array}{l}53(79.1) \\
14(20.9)\end{array}$ \\
\hline $\begin{array}{l}\text { LDLc }(\mathrm{mg} / \mathrm{dL}) \mathrm{n}(\%) \\
\quad<160 \text { normal } \\
\geq 160 \text { abnornal }\end{array}$ & $\begin{array}{l}61(91.0) \\
6(9.0)\end{array}$ \\
\hline $\begin{array}{l}\text { Viral load (copies/mL), n (\%) } \\
\quad<50 \\
50-1,000 \\
1,000-100,000 \\
>100,000\end{array}$ & $\begin{array}{c}0(0.0) \\
5(7.5) \\
45(67.2) \\
17(25.4)\end{array}$ \\
\hline
\end{tabular}

Continue... 
TABLE 1: Continuation.

\begin{tabular}{|c|c|}
\hline Variables & Number=67 \\
\hline $\begin{array}{l}\text { Time between diagnosis and initiation of treatment (months) } \\
\text { median* }^{*}\end{array}$ & $4.60(2.10 ; 10.80)$ \\
\hline $\begin{array}{l}\mathrm{BMI}\left(\mathrm{kg} / \mathrm{m}^{2}\right) \\
\text { median* }^{*}\end{array}$ & $24.00(21.67 ; 26.85)$ \\
\hline
\end{tabular}

CAGE: the CAGE questionnaire; SBP: systolic blood pressure; DBP: diastolic blood pressure; BP: blood pressure; HDLc: high density cholesterol; LDLc: low density cholesterols; CD4: Iymphocytes CD4+; BMI: body mass index. *Interquartile range.

TABLE 2: Carotid ultrasonography findings and Framingham score of people living with HIV before antiretroviral therapy treatment in a reference center, Belo Horizonte, State of Minas Gerais, March 2014 - September 2015.

\begin{tabular}{|c|c|}
\hline Variables & Number $=67$ \\
\hline $\begin{array}{r}\text { Mean CIMT } \\
\text { mean } \pm S D\end{array}$ & $494.08 \pm 96.84$ \\
\hline $\begin{array}{l}\text { CIMT percen } \\
<2.5 \\
2.5-10 \\
10.1-25 \\
25.1-50 \\
50.1-75 \\
75.1-90 \\
90.1-97.5 \\
>97.5\end{array}$ & $\begin{array}{c}0(0.0) \\
5(7.5) \\
8(11.9) \\
22(32.8) \\
21(31.3) \\
4(6.0) \\
6(9.0) \\
1(1.5)\end{array}$ \\
\hline $\begin{array}{l}\text { Framingham } \\
\text { low } \\
\text { moderate } \\
\text { high }\end{array}$ & $\begin{array}{c}54(80.6) \\
9(13.4) \\
4(6.0)\end{array}$ \\
\hline
\end{tabular}

HIV: human immunodeficiency virus; SD: standard deviation; VAC: vascular age calculator; CIMT: carotid intima-media thickness. ${ }^{*} p=0.0198$. 
TABLE 3: Results of receiver operating characteristic curve analysis of biomarkers, BMI and VL related to cardiovascular risks.

\begin{tabular}{lccc}
\hline Variable & AUC & 95\% CI of AUC & p-value \\
\hline BMI & $\mathbf{0 . 6 9}$ & $\mathbf{0 . 5 2} ; \mathbf{0 . 8 6}$ & $\mathbf{0 . 0 3}$ \\
VL & 0.64 & $0.49 ; 0.80$ & 0.11 \\
sVCAM-1 & 0.51 & $0.35 ; 0.67$ & 0.89 \\
ADAMTS13 & 0.55 & $0.37 ; 0.73$ & 0.60 \\
D-Dimer & $\mathbf{0 . 3 3}$ & $\mathbf{0 . 1 8} ; \mathbf{0 . 4 8}$ & $\mathbf{0 . 0 6}$ \\
GDF15 & 0.44 & $0.28 ; 0.61$ & 0.53 \\
sICAM & 0.37 & $0.22 ; 0.52$ & 0.16 \\
MPO & 0.64 & $0.48 ; 0.80$ & 0.11 \\
P-Selectin & $\mathbf{0 . 3 3}$ & $\mathbf{0 . 1 7} ; \mathbf{0 . 4 9}$ & $\mathbf{0 . 0 6}$ \\
Lipocalin-2NGAL & 0.50 & $0.31 ; 0.70$ & 0.99 \\
SAA & 0.53 & $0.35 ; 0.71$ & 0.74 \\
Myoglobin & 0.53 & $0.35 ; 0.72$ & 0.71 \\
\hline
\end{tabular}

BMI: body mass index; VL: viral load; 95\% Cl: confidence interval $95 \%$; AUC: area under the curve; $\mathbf{C I}$ : confidence interval; sVCAM-1: vascular adhesion molecule1; ADAMTS13: Disintegrin and Metalloproteinase with Thrombospondin motifs; GDF15: growth differentiation factor 15; sICAM: soluble molecule of intercellular adhesion; MPO: myeloperoxidase; 2NGAL: vascular growth factors angiopoietin; SAA: serum amyloid A.

the intima-media thickness, and without statistical significance, i.e. $\beta=-5.57$ (95\% confidence interval: $-12.31-1.18), p=0.10$. There was an association between measured thickness and cardiovascular risk and age.

\section{DISCUSSION}

The majority of participants were male and MSM with a mean age of 32 years. Being a young population, there were low prevalences of arterial hypertension and diabetes mellitus. However, the prevalence of smoking was higher than that reported in Brazilian national surveys ${ }^{40-43}$. In addition, we found a high (70\%) prevalence of dyslipidemia, mainly with high density lipoprotein cholesterol reduction, despite the young population and prior $\mathrm{ART}^{44}$, which can be explained, among other factors by the alteration in the maturation of this lipoprotein caused by the direct action of HIV ${ }^{45,46}$. All efforts should be made to promote health and disease prevention in this population, aiming to reduce the classical factors of chronicdegenerative diseases, mainly smoking cessation. Regarding the immunological statuses of the patients, the majority had LTCD4+ counts above 400 cells $/ \mathrm{mm}^{3}$, considered adequate and higher than those reported in another study in Brazil ${ }^{46}$. There was no association between biomarkers and cardiovascular risk.

There was an association between the measured thickness, the cardiovascular risk, and the age. Age showed a positive correlation with the intima-media thickness; older patients had thicker intima-media. This result corroborates findings from the literature on risk factors of mean $\mathrm{CIMT}^{25}$.

The sample size may have been insufficient to show the relationship between biomarker changes and other classic cardiovascular risk factors, such as age, tabagism and immunological status, as evidenced in the literature ${ }^{7,12,32}$.

In this cross-sectional study, associated factors and effects were evaluated simultaneously. Therefore, this study only allows the establishment of associations between events, and it is not possible to define causality. No sedentary lifestyle was evaluated in this population, and no association could be made between physical activity and cardiovascular risk in the described population. Another limitation of the study is the absence of a control group of healthy participants in order to compare serum levels of studied biomarkers, due to the absence of reference values in the literature.

In this study, we noted a high $(70.4 \%)$ prevalence of dyslipidemia in relation $(60.3 \%)$ to the general Brazilian population. This level of change was found prior to the individual's exposure to ART and tended to increase significantly with the initiation of therapy, since most ART negatively modify the user's long-term lipid profile, gradually increasing cardiovascular risk over time.

There was no association between cardiovascular biomarkers and carotid atherosclerosis, similar to other studies that did not find such an association ${ }^{48}$. We identified early changes in the intima-media thickness and the increase in the vascular age calculated in the majority of participants, similar to other studies $^{49}$. This result points to the role of HIV itself in the pathogenesis of atherosclerotic disease since the population studied was young, most of them were without classical risk factors, and were all without previous ART exposure. Prospective studies are needed to confirm this tendency. The intima-media thickness was directly associated with the age of the participants, a finding that corroborates those of the current literature, and shows that age is a risk factor for the increase in intima media thickness. The intima-media thickness seems to be a good marker for subclinical arteriosclerosis in the HIV population, as it is already in the general population. We suggest that prospective studies evaluate the effectiveness of inclusion of this variable in the care protocols for PLWHIV.

\section{Conflict of interest}

The authors declare that there is no conflict of interest.

\section{Financial support}

Fundação de Amparo à Pesquisa do Estado de Minas Gerais: Edital Universal 2014.

\section{REFERENCES}

1. The Joint United Nations Programme on HIV/AIDS (UNAIDS). Global AIDS Update 2016. Available in: http://www.unaids.org/ sites/default/files/media_asset/global-AIDS-update-2016_en.pdf

2. Palella Jr FJ, Delaney KM, Moorman AC, Loveless MO, Fuhrer J, Satten GA, et al. Declining morbidity and mortality among patients with advanced human immunodeficiency virus infection. HIV Outpatient Study Investigators. N Engl J Med. 1998;338(13):853-60.

3. Deeks SG, Phillips AN. HIV infection antiretroviral treatment, aging and non-AIDS related morbidity. BMJ. 2009;338:a3172.

4. The Antiretroviral Therapy Cohort Collaboration (ART-CC). Life expectancy of individuals on combination antiretroviral therapy in high-income countries: a collaborative analysis of 14 cohort studies. Lancet. 2008;372(9635):293-99. 
5. Valdez H, Tanvir KC, Robert A, Ian JW, Tracy D, Robin D, et al. Changing spectrum of mortality due to human immunodeficiency virus: analysis of 260 deaths during 1995-1999. Clin Infect Dis. 2001;32(10):1487-93.

6. Powderly W. Growing old with HIV - dealing with co-morbidities. Journal of the International AIDS Society 2010;13(Suppl 4):O25.

7. Rodger AJ, Lodwick R, Schechter M, Deeks S, Amin J, Gilson R, et al. Mortality in well controlled HIV in the continuous antiretroviral therapy arms of the SMART and ESPRIT trials compared with the general population. AIDS. 2013;27(6):973-9.

8. Baker JV, Peng G, Rapkin J, Abrams DI, Silverberg MJ, MacArthur $\mathrm{RD}$, et al. CD4+ count and risk of non-AIDS diseases following initial treatment for HIV infection. AIDS. 2008;22(7):841-8.

9. Aberg JA. Aging, inflammation and HIV infection. Top Antivir Med. 2012;20(3):101-5.

10. Deeks SG. HIV infection, inflammation, immunosenescence, and aging. Annu Rev Med. 2011;62:141-55.

11. Phillips AN, Carr A, Neuhaus J, Visnegarwala F, Prineas R, Burman WJ, et al. Interrupition of antiretroviral therapy and risk of cardiovascular diseases in persons with HIV-1 infection: exploratory analyses from the SMART trial. Antivir Ther. 2008;13(2):177-87.

12. Kuller LH, Tracy R, Belloso W, De Wit S, Drummond F, Lane HC, et al. Inflammatory and coagulation biomarkers and mortality in patients with HIV infection. PLoS Med. 2008;5(10):e203.

13. Freiberg MS, Bebu I, Tracy R, So-Armah K, Okulicz J, Ganesan A, et al. D-dimer levels before HIV seroconversion remain elevated even after viral suppression and are associated with an increased risk of non-AIDS events. PLoS ONE. 2016;11(4):e0152588.

14. El-Sadr WM, Lundgren JD, Neaton JD, Gordin F, Abrams D, Arduino RC, Strategies for Management of Antiretroviral Therapy (SMART) Study Group1, et al. CD4 ${ }^{+}$count-guided interruption of antiretroviral treatment. N Engl J Med. 2006;355(22):2283-96.

15. Triant VA, Lee H, Hadigan C, Grinspoon SK. Increased acute myocardial infarction rates and cardiovascular risk factors among patients with human immunodeficiency virus disease. J Clin Endocrinol Metab. 2007;92(7):2506-12.

16. Stein JH. Cardiovascular risk and dyslipidemia management in HIV-infected patients. Top Antivir Med. 2012;20(4):129-33.

17. Grinspoon SK. Cardiovascular disease in HIV: traditional and nontraditional risk factors. Top Antivir Med. 2014;22(4):676-9.

18. Stein JH, Currier JS, Hsue PY. Arterial disease in patients with human immunodeficiency virus infection: what has imaging taught us? JACC Cardiovascular imaging. 2014;7(5):515-25.

19. Klein DB, Leyden WA, Xu L, Chao CR, Horberg MA, Towner WJ, et al. Declining relative risk for myocardial infarction among HIVpositive compared with HIV-negative individuals with access to care. Clin Infect Dis. 2015;60(8):1278-80.

20. Freiberg MS, Chang CH, Kuller LH, Skanderson M, Lowy E, Kraemer KL, et al. HIV infection and the risk of acute myocardial infarction. JAMA Intern Med. 2013;173(8):614-22.

21. Lang S, Mary-Krause M, Cotte L, Gilquin J, Partisani M, Simon A, et al. Increased risk of myocardial infarction in HIV-infected patients in France, relative to the general population. AIDS. 2010;24(8):1228-30.

22. Bahrami H, Budoff M, Haberlen SA, Rezaeian P, Ketlogetswe K, Tracy R, et al. Inflammatory markers associated with subclinical coronary artery disease: The multicenter AIDS cohort study. J Am Heart Assoc. 2016;5(6)pii:e003371.

23. Stein JH, Korcarz CE, Hurst RT, Lonn E, Kendall CB, Mohler $\mathrm{ER}$, et al. Use of carotid ultrasound to identify subclinical vascular disease risk: a consensus satement from the American Society of Echocardiography Carotid Intima-Media Thickness Task Force. Endorsed by the Society for Vascular Medicine. J Am Soc Echocardiogr. 2008;21(2):93-111.

24. Polak, J. Carotid intima-media thickness; an early marker of cardiovascular disease. Ultrasound Q. 2009;25(2):55-61.

25. Tattersall MC, Gassett A, Korcarz CE, Gepner AD, Kaufman JD, Liu KJ, et al. Predictors of carotid thickness and plaque progression during a decade: the Multi-Ethnic Study of Atherosclerosis (MESA). Stroke. 2014;45(11):3257-62.

26. Engelen L, Ferreira I, Stehouwer CD, Boutouyrie P, Laurent S; Reference Values for Arterial Measurements Collaboration. Reference intervals for common carotid intima-media thickness measured with echotracking: relation with risk factors. Eur Heart J. 2013;34(30):2368-80.

27. Hulten E, Mitchell J, Scally J, Gibbs B, Villines TC. HIV positivity, protease inhibitor exposure and subclinical artheroscleroses: a systemic review and metanalysis of observation studies. Heart. 2009;95(22):1826-32.

28. Grunfeld C, Delaney JAC, Wanke C, Currier JS, Scherzer R, Biggs ML, et al. Preclinical atherosclerosis due to HIV infection: carotid intima-medial thickness measurements from the FRAM study. AIDS. 2009;23(14):1841-9.

29. Tien PC, Benson C, Zolopa AR, Sidney S, Osmond D, Grunfeld C, et al. The study of fat redistribution and metabolic change in HIV infection (FRAM): methods, design, and sample characteristics. Am J Epidemiol. 2006;63(9):860-9.

30. Bosch RJ, Zhang X, Sandler NG. Study design issues in evaluating immune biomarkers. Curr Opin HIV AIDS. 2013;8(2):147-54.

31. Guimarães MMM, Greco DB, O Júnior AR, Penido MG, Machado LJC. Distribuição da gordura corporal e perfis lipídico e glicêmico de pacientes infectados pelo HIV. Arq Bras Endocrinol Metab. 2007;51(1):42-51.

32. Graham SM, Rajwans N, Tapia KA, Jaoko W, Estambale BB, McClelland RS, et al. A prospective study of endothelial activation biomarkers, including plasma angiopoietin-1 and angiopoietin-2, in Kenyan women initiating antiretroviral therapy. BMC Infect Dis. 2013;13:263-68.

33. Papasavvas E, Azzoni L, Pistilli M, Hancok A, Reynolds G, Gallo C, et al. Increased soluble vascular cell adhesion molecule-1 plasma levels and soluble intercellular adhesion molecule-1 during antiretroviral therapy interruption and retention of elevated soluble vascular cellular adhesion molecule-1 levels following resumption of antiretroviral therapy. AIDS. 2008;22(10):1153-61.

34. Borges AH, O'Connor JL, Phillips AN, Baker JV, Vjecha MJ, Losso $\mathrm{MH}$, et al. Factors Associated with D-Dimer Levels in HIV-Infected Individuals. PLoS One. 2014;9(3):e90978.

35. Vos AG, Idris NS, Barth RE, Klipstein-Grobusch K, Grobbee DE. Pro-inflammatory markers in relation to cardiovascular disease in HIV infection. A systematic review. PLoS One. 2016;11(1):e0147484.

36. Willians N. The CAGE questionnaire. Occup Med. 2014;64(6):473-4.

37. MILliPLEX MAP. Human Cardiovascular Disease (CVD) Magnetic Bead Panel 2 - Cardiovascular Disease Multiplex Assay, HCVD2MAG-67K. Darmstadt: Available in: http://www. merckmillipore.com/BR/pt/product/MILLIPLEX-MAP-HumanCardiovascular-Disease-\%28CVD\%29-Magnetic-Bead-Panel-2--Cardiovascular-Disease-Multiplex-Assay,MM_NF-HCVD2MAG$67 \mathrm{~K}$ ?ReferrerURL=https $\% 3 \mathrm{~A} \% 2 \mathrm{~F} \% 2 \mathrm{Fw} w$ w.google.com. br\%2F\&bd=1\#anchor_REF

38. Stein JH, Fraizer MC, Aeschlimann SE, Nelson-Worel J, McBride PE, Douglas PS. Vascular age: Integrating carotid intima-media 
thickness measurements with global coronary risk assessment. Clin Cardiol. 2004;27(7):388-92.

39. Howard G, Sharrett AR, Heiss G, Evans GW, Chambless LE, Riley WA, et al. Carotid artery intimal-medial thickness distribution in general populations as evaluated by B-mode ultrasound. Stroke. 1993;24(9):1297-304.

40. Instituto Brasileiro de Geografia e Estatistica (IBGE). Pesquisa Nacional de Saúde 2013: Percepção do estado de saúde, estilos de vida e doenças crônicas. Rio de Janeiro: IBGE; 2014. 181p. Disponível em: http://biblioteca.ibge.gov.br/visualizacao/livros/liv91110.pdf

41. Granjeiro A, Escuder MM, Cassanote AJF, Souza RA, Kalichman AO, Veloso VG, et al. The HIV-Brazil Cohort Study: Design, Methods and Participant Characteristics. PLoS One. 2014;9(5):e95673.

42. Chor D, Ribeiro ALP, Sá CM, Duncan BB, Andrade LP, Araújo $\mathrm{AN}$, et al. Prevalence, awareness, treatment and influence of socioeconomic variables on control of high blood pressure: results of the ELSA-Brasil Study. PLoS One. 2015;10(6):e0127382.

43. Santos IS, Alencar AP, Rundek T, Goulart AC, Barreto SM, Pereira $\mathrm{AC}$, et al. Low impact of traditional risk factors on carotid intimamedia thickness. The ELSA-Brasil Cohort. Arterioscler Thromb Vasc Biol. 2015;35(9):2054-59

44. Siegel MO, Borkowska AG, Dubrovsky L, Roth M, Welti R, Roberts $\mathrm{AD}$, et al. HIV infection induces structural and functional changes in high density lipoproteins. Atherosclerosis. 2015;243(1):19-29.

45. Rose H, Hoy J, Woolley I, Tchoua U, Bukrinsky M, Dart A, et al. HIV infection and high density lipoprotein metabolism. Atherosclerosis. 2008;199(1):79-86.

46. Ministério da Saúde (MS). Departamento de Vigilância em Saúde. Departamento de DST, AIDS e Hepatites Virais. Clinical protocol and therapeutic guidelines for management of HIV infection in adults. Brasília: MS; 2015. Disponível em: http:// www.aids.gov.br/sites/default/files/anexos/publicacao/2013/55308/ protocolofinal_31_7_2015_pdf_31327.pdf

47. Valentini MB, Toledo ML, Fonseca MO, Thiersch LM, Toledo ISB, Machado FC, et al. Evaluation of late presentation for HIV treatment in a reference center in Belo Horizonte, Southeastern Brazil, from 2008 to 2010. Braz J Infect Dis. 2015;19(3):253-62

48. Lacerda HR, Falcão MC, de Albuquerque VM, Zírpoli JC, .Miranda-Filho DB, de Albuquerque MF, et al. Association of inflammatory cytokines and endothelial adhesion molecules with immunological, virological, and cardiometabolic disease in HIVinfected individuals. J Interferon Cytokine Res. 2014;34(5):385-93.

49. Godoi ET, Brandt CT, Lacerda HR, Godoi JT, Oliveira DC, Costa $\mathrm{GF}$, et al. Intima-media thickness in the carotid and femoral arteries for detection of arteriosclerosis in human immunodeficiency viruspositive individuals. Arq Bras Cardiol. 2017;108(1):3-11. 